\title{
Antibiotic resistance and prevalence of class 1 and 2 integrons in Escherichia coli isolated from hospital wastewater
}

\author{
Reza Ranjbar*, Maryam Zeynali**, Nooshin Sohrabi***, Asghar Ali Kamboh \\ and Arman Moshaveri ${ }^{\dagger+}$
}

\begin{abstract}
\section{BACKGROUND}

Hospital wastewaters may contain antibiotic resistant bacteria such as Escherichia coli. These E. coli harbor integron genes that are responsible for antibiotic resistance. The purpose of the current study was to evaluate the frequency of class 1 and 2 integrons in environmental antibiotic resistant E. coli strains isolated from the hospital wastewaters in Tehran, Iran.

\section{METHODS}

As a descriptive cross-sectional study, this research was performed from April to September 2015 on hospital wastewaters in Tehran. Bacterial isolation and identification was performed by standard biochemical and bacteriological procedures. Susceptibility testing was done by employing the disk diffusion method using different antibiotics. Total DNAs were extracted to evaluate the presence of class 1 and 2 integrons by using the polymerase chain reaction (PCR) method with specific primers.
\end{abstract}

\section{RESULTS}

Fifty E. coli strains were isolated and identified from the wastewaters of 25 hospitals in Tehran. The phenotype results showed that 46 isolates (92\%) were resistant to at least one antibiotic and 27 isolates (54\%) were multidrug resistant. PCR showed that $35(70 \%)$ and $20(40 \%)$ of the isolates had class 1 and 2 integrons respectively and 14 isolates (28\%) had both class 1 and class 2 integrons.

\section{CONCLUSION}

This study has shown a considerable presence of class 1 and class 2 integrons in E. coli strains isolated from hospital wastewaters in Tehran. Proper antibiotics prescription and appropriate hospital wastewater treatment can prevent resistance genes in E. coli from circulating in the environment.

Keywords: Escherichia coli, integron, antibiotic-resistant, hospital wastewaters

\author{
*Molecular Biology Research Center, \\ Systems Biology and Poisonings \\ Institute, Baqiyatallah University of \\ Medical Sciences, Tehran, Iran \\ **Department of Microbial \\ Biotechnology, Payame Noor \\ University, Tehran, Iran \\ *** Department of Biology, Payame \\ Noor University, Tehran, Iran \\ 'Department of Veterinary \\ Microbiology, Faculty of Animal \\ Husbandry and Veterinary Sciences, \\ Sindh Agriculture University, \\ Tandojam 70060, Pakistan \\ ${ }^{\top} D V M$, Faculty of Veterinary \\ Medicine, Karaj Branch, Islamic Azad \\ University, Karaj, Iran
}

\section{Correspondence}

Reza Ranjbar

Molecular Biology Research Center, Systems Biology and Poisonings Institute, Baqiyatallah University of Medical Sciences, Tehran, Iran Tel/fax: 00982188039883

Email:ranjbarre@gmail.com ORCID ID: orcid.org/0000-00018593-1514

Date of first submission, May 30, 2018 Date of final revised submission, November 26, 2018

Date of acceptance, November 30, 2018

This open access article is distributed under a Creative Commons AttributionNon Commercial-Share Alike 4.0 International License 


\section{INTRODUCTION}

Water that has been produced for specific consumptions and the quality of which has deteriorated after use, is called wastewater. In hospitals, clean water is used in various sections to safeguard patients' health. As a result, water quality diminishes and is therefore converted to wastewaters. ${ }^{(1)}$ The widespread use of antibiotics has led to an increase in the global dispersion of bacteria that are resistant to antibiotics. Furthermore, due to an increase in the use of antibiotics in hospitals, hospital wastewaters now contain large numbers of bacteria that are resistant to antibiotics, including E.coli. ${ }^{(2)}$ Drug-resistant strains of E.coli can lead to problems in the management and control of intra- and extra-intestinal infections caused by these bacteria. E.coli is a commensal bacterium and is part of the normal flora of the human gut. The Gram-negative bacterium E. coli is nonpathogenic but can cause diseases and diarrhea when virulence factors like adhesins and endotoxin are available. ${ }^{(3-5)}$ Intestinal infection pathotypes of E.coli comprise enteroaggregative E.coli (EAEC), enterotoxigenic E.coli (ETEC), enteropathogenic E.coli (EPEC), enteroinvasive E.coli (EIEC), enterohemorrhagic E.coli (EHEC), cell-detaching E.coli (CDEC), and diffusely adherent E.coli (DAEC). Extraintestinal pathogenic E.coli (ExPEC) can cause serious and dangerous diseases such as urinary tract infection, meningitis and septicemia. ${ }^{(6-8)}$

The development of drug resistance can occur by the horizontal transfer of antimicrobial resistance genes through mobile genetic elements. ${ }^{(9)}$ Integrons are one of the mobile genetic elements that play a significant role in the acquisition and dissemination of antimicrobial resistance genes. ${ }^{(10)}$ They have been also associated with other mobile genetic elements such as transposons and plasmids. The role of integrons and gene cassettes in the development of drug resistance in Gram-negative bacteria has been proven. ${ }^{(11)}$ All integrons consist of three sections, including the gene for the integron integrase (intI), integron-associated recombination site (attl) and integron-carried promoter $(\mathrm{Pc})$. Integrons have been associated with other mobile genetic elements and resistance genes which cause their spread among bacteria in the environment that are exposed to antibiotics. Five classes of integrons have been established that are known based on integrase enzyme coding sequence. Class 1,2 and 3 integrons are more frequent in multiple drug resistance. ${ }^{(12)}$ The class 1 integron has two conserved segments (52 -CS and 32 -CS). The 32 -CS region has the qacE"1 gene (which causes resistance to quaternary ammonium compounds) and also has the sull gene which causes resistance to sulfonamides. Class 2 integrons are related to transposon $\mathrm{Tn} 7$ and carry six resistance gene cassettes. ${ }^{(13)}$ Gene cassettes that encode antibiotic resistance genes have 59base elements, the specific sites for recombination. Gene cassettes related to class 1,2 and 3 integrons are associated with resistance to aminoglycosides, chloramphenicol, $\beta$-lactamase, trimethoprim and other antibiotics. ${ }^{(14,15)}$

Some limited previous studies have reported antibiotic resistance of $E$. coli strains isolated from sewage or wastewaters. Reinthaler et al. ${ }^{(16)}$ reported that $12 \%$ of $E$. coli strains isolated from sewage and sludge were resistant to trimethoprim/sulfamethoxazole and $57 \%$ to tetracycline. Elmanama et al. ${ }^{(17)}$ reported that $31.9 \%$ of E.coli strains isolated from hospital wastewater were resistant to tetracycline, $10.6 \%$ to amikacin, $25.8 \%$ to co-trimoxazole and $12.8 \%$ to chloramphenicol. Low resistance rates to trimethoprim/sulfamethoxazole (12.24\%) and chloramphenicol (32.65\%) are reported in E. coli strains isolated from hospital wastewater in Hamadan, Iran by Hadi et al., ${ }^{(18)}$ while Gündogdu et al. ${ }^{(19)}$ reported high rates of resistant isolates against imipenem (84\%) and tetracycline (94\%).

To the best of our knowledge, little is known about the integrons and their associated gene cassettes in E.coli strains isolated from hospital wastewaters specifically and in Tehran city 
generally. The aim of this study was to appraise antibiotic resistance and the presence of class 1 and 2 integrons in E.coli strains isolated from hospital wastewaters.

\section{METHODS}

\section{Study design}

A descriptive cross-sectional study was performed from April to September 2015 on the hospital wastewaters in various parts of Tehran city, Iran.

\section{Bacterial isolates}

The hospital wastewater samples were collected from 25 hospitals located in various parts of Tehran city, Iran. E.coli isolates were identified and isolated by standard microbiological methods. ${ }^{(20)}$ Wastewater samples were cultured on Chrom agar (Merck, Germany) and plates were incubated at $37^{\circ} \mathrm{C}$ for 18 hours, then suspected purple colonies were subcultured to EMB agar (Merck, Germany) and incubated at $37^{\circ} \mathrm{C}$ for 18 hours to confirm the presence of $E$. coli isolates, and finally the isolates were kept as E. coli at $-20^{\circ} \mathrm{C}$ for more investigations.

\section{Antimicrobial susceptibility testing}

Antimicrobial susceptibility testing of total $E$. coli isolates was done by the disc diffusion method according to the Clinical Laboratory
Standard Institute (CLSI) instructions. ${ }^{(21)}$ Antibiotic discs that were used in this study included tetracycline (TE, 30 $\mu$ g), co-trimoxazole (SXT, 1.25/ $23.75 \mu \mathrm{g}$ ), chloramphenicol (C, 30 $\mu \mathrm{g}$ ), amikacin (AN, $30 \mu \mathrm{g}$ ), nitrofurantoin (FM, $300 \mu \mathrm{g}$ ), imipenem (IPM, $10 \mu \mathrm{g}$ ) and streptomycin $(\mathrm{S}, 10 \mu \mathrm{g})$. Bacterial suspensions of isolates were prepared based on McFarland standard No. 0.5 and were cultured on Mueller-Hinton agar (Merk, Germany). Afterwards the plates were kept at $37^{\circ} \mathrm{C}$ overnight, the inhibition zone diameter was measured and the results were reported based on the CLSI table as sensitive, intermediate and resistant.

\section{Polymerase chain reaction (PCR)}

Total DNA samples were extracted by the boiling method. Class 1 and class 2 integrons were detected by using the PCR method with specific primers. Primer sequence, sizes of PCR products and PCR programs are shown in Table 1. The PCR was performed in a total volume of $20 \mu \mathrm{l}$, comprising $10 \mu 1$ master mix (Taq DNA polymerase, dNTP and $\mathrm{MgCl}_{2}$; Ampliqon, Finland), $1 \mu$ lemplate DNA, $1 \mu$ l of each primer and $7 \mu 1$ sterile deionized water. The amplified products were then examined by electrophoresis on $1.5 \%$ agarose gel (Merck, Germany) in TBE (Tris base-Boric acid-EDTA) $1 \mathrm{X}$ buffer and gels were stained with Simplysafe stain (EURx, Finland) then visualized under ultraviolet light.

Table 1. Primer sequence and size, and PCR programs

\begin{tabular}{|c|c|c|c|c|}
\hline $\begin{array}{l}\text { Gene } \\
\text { class }\end{array}$ & Primer sequence & $\begin{array}{l}\text { Size } \\
\text { (bp) }\end{array}$ & PCR programs & Reference \\
\hline $\begin{array}{l}\text { Class } 1 \\
\text { integron } \\
(\text { Int } 1)\end{array}$ & $\begin{array}{c}\text { F:5'-GGGTCAAGGATCTGGATTTCG- } \\
\text { 3' } \\
\text { R:5'-ACATGGGTGTAAATCATCGTC- } \\
3^{\prime}\end{array}$ & 484 & $\begin{array}{l}\text { Initial denaturation at } 95^{\circ} \mathrm{C} \\
\text { for } 5 \text { min., } 30 \text { cycles of } \\
\text { denaturation at } 94^{\circ} \mathrm{C} \text { for } 50 \mathrm{~s} \text {, } \\
\text { primer annealing at } 52^{\circ} \mathrm{C} \text { for } \\
50 \mathrm{~s} \text {, and primer extension at } \\
72^{\circ} \mathrm{C} \text { for } 1 \text { min. } \\
\text { Final extension at } 72^{\circ} \mathrm{C} \text { for } 5 \\
\text { min. }\end{array}$ & $\begin{array}{l}\text { Roe et } \\
\text { al. }{ }^{(22)}\end{array}$ \\
\hline $\begin{array}{l}\text { Class } 2 \\
\text { integron } \\
(\text { Int } 2)\end{array}$ & $\begin{array}{l}\text { F:5'-GCAAATGAAGTGCAACGC-3' } \\
\text { R:5'-ACACGCTTGCTAACGATG-3' }\end{array}$ & 466 & $\begin{array}{l}\text { Initial denaturation at } 95^{\circ} \mathrm{C} \\
\text { for } 4 \text { min., } 30 \text { cycles of } \\
\text { denaturation at } 94^{\circ} \mathrm{C} \text { for } 50 \mathrm{~s} \text {, } \\
\text { primer annealing at } 52^{\circ} \mathrm{C} \text { for } \\
50 \mathrm{~s} \text {, and primer extension at } \\
72^{\circ} \mathrm{C} \text { for } 1 \text { min. Final } \\
\text { extension at } 72^{\circ} \mathrm{C} \text { for } 5 \mathrm{~min} \text {. }\end{array}$ & Sunde ${ }^{(23)}$ \\
\hline
\end{tabular}


Table 2. Distribution of antibiotic susceptibility and resistance

\begin{tabular}{|c|c|c|c|c|c|c|c|}
\hline \multirow{2}{*}{$\begin{array}{c}\text { Antibiotic } \\
\text { Agent }\end{array}$} & \multicolumn{3}{|c|}{$\begin{array}{l}\text { Total susceptibility of isolates } \\
\qquad(\mathrm{n}=\mathbf{5 0})\end{array}$} & \multirow{2}{*}{$\begin{array}{c}\mathbf{R} \\
\text { Integron } \\
\text { negative } \\
(\mathbf{n}=9) \\
\mathbf{n}(\%) \\
\end{array}$} & \multirow{2}{*}{$\begin{array}{c}R \\
\text { Integron } \\
\text { positive } \\
(n=41) \\
n(\%) \\
\end{array}$} & \multirow{2}{*}{$\begin{array}{c}\mathbf{R} \\
\text { Integron } \\
\text { class } 1 \\
(\mathbf{n}=35) \\
\mathbf{n}(\%) \\
\end{array}$} & \multirow{2}{*}{$\begin{array}{c}\mathbf{R} \\
\text { Integron } \\
\text { class } 2 \\
(\mathrm{n}=\mathbf{2 0}) \\
\mathrm{n}(\%)\end{array}$} \\
\hline & $\begin{array}{c}\mathbf{R} \\
\mathbf{n}(\%)\end{array}$ & $\begin{array}{c}\text { I } \\
\text { n }(\%)\end{array}$ & $\begin{array}{c}\mathrm{S} \\
\mathrm{n}(\%)\end{array}$ & & & & \\
\hline Chloramphenicol & $13(26)$ & $3(6)$ & $34(68)$ & $2(22.2)$ & $11(26.8)$ & $8(22.9)$ & $7(35)$ \\
\hline Tetracycline & $22(44)$ & $5(10)$ & $23(46)$ & $1(11.1)$ & $21(51.2)$ & $18(51.4)$ & $9(45)$ \\
\hline Streptomycin & $29(58)$ & $8(16)$ & $13(26)$ & $3(33.3)$ & $26(63.4)$ & $23(65.7)$ & $14(70)$ \\
\hline Amikacin & $1(2)$ & $1(2)$ & $48(96)$ & $1(11.1)$ & - & - & - \\
\hline Co-trimoxazole & $24(48)$ & $4(8)$ & $22(44)$ & $5(55.5)$ & $19(46.3)$ & $17(48.6)$ & $11(55)$ \\
\hline Nitrofurantoin & 7 (14) & $5(10)$ & $38(76)$ & $1(11.1)$ & $6(14.6)$ & $6(17.1)$ & $2(10)$ \\
\hline Imipenem & 24 (48) & $14(28)$ & $12(24)$ & $4(44.4)$ & $20(47.8)$ & $20(57.1)$ & $8(40)$ \\
\hline
\end{tabular}

R: Resistant, I: Intermediate, S: Sensitive

\section{RESULTS}

Fifty strains of E.coli were isolated from the different 25 hospital wastewater samples collected from Tehran city. The results obtained from antibiotic susceptibility of isolates showed that 46 isolates $(92 \%)$ were resistant to at least one antibiotic and 27 isolates (54\%) of the 46 isolates were multidrug resistant. Also the highest percentages of antibiotic resistance in isolates were related to streptomycin (58\%), imipenem $(48 \%)$ and co-trimoxazole $(48 \%)$ while the lowest percentages were associated with nitrofurantoin (14\%) and amikacin (2\%) (Table $2)$. The results obtained from PCR showed that $35(70 \%)$ isolates had class 1 integrons and 20 isolates (40\%) had class 2 integrons. In addition, $65.7 \%, 57.1 \%$ and $17.1 \%$ of isolates harboring class 1 integrons were resistant to streptomycin, imipenem and nitrofurantoin, respectively. Also $70 \%, 55 \%$ and $10 \%$ of isolates harboring class 2 integrons were resistant to streptomycin, cotrimoxazole and amikacin.

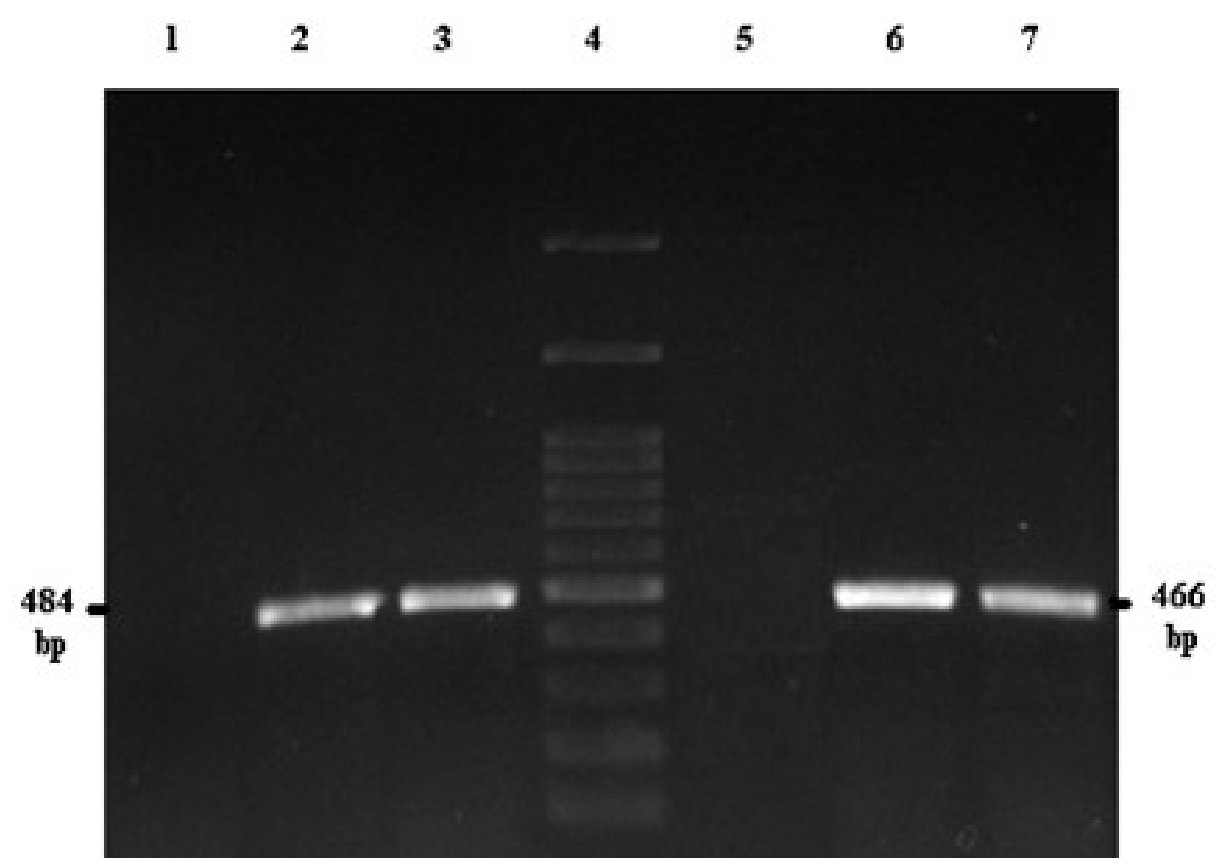

Figure 1. PCR detection of class 1 and 2 integrons. PCR products of class 1 integron (lane 2 and 3, integron positive, and lane 1, integron negative); lane 4: molecular marker (100 bp); PCR products of class 2 integron (lane 6 and 7, integron positive, and lane 5, integron negative) 


\section{DISCUSSION}

Among Gram-negative bacteria, E. coli is known to be a leading cause of nosocomial infections globally. Control of E.coli illnesses has become especially challenging due to emergence of multidrug resistant strains. ${ }^{(24)}$ Previous research has suggested that antibiotic resistant bacteria enter the water environment from the various ecosystems like humans or animals $\rightarrow$ soil $\rightarrow$ water ${ }^{(25)}$ and that unsafe water has contributed to $3.2 \%$ deaths worldwide. ${ }^{(26)}$ The fecal bacteria in the water environment might transfer antibiotic resistance to autochthonous bacteria through lateral transfer of movable genetic elements. ${ }^{(27)}$ Furthermore, indirect evidences of the transmission of antibiotic resistance genes in aquatic habitats are also extant. ${ }^{(28)}$ In the current study we have explored the antimicrobial profile of E.coli isolates of hospital wastewaters. The results of the antibiotic susceptibility testing showed that $26 \%$ of the isolates were resistant to chloramphenicol, $44 \%$ to tetracycline, $58 \%$ to streptomycin, $2 \%$ to amikacin, $48 \%$ to co-trimoxazole, $14 \%$ to nitrofurantoin and $48 \%$ to imipenem. Reinthaler et al. ${ }^{(16)}$ noted that $12 \%$ of their isolates were resistant to trimethoprim/ sulfamethoxazole and $57 \%$ to tetracycline, therefore in comparison with our study, the resistance to tetracycline in their study was the highest. Another research study was done by Elmanama et al. ${ }^{(17)}$ who reported that $31.9 \%$ of E.coli isolates were resistant to tetracycline, $10.6 \%$ to amikacin, $25.8 \%$ to cotrimoxazole and $12.8 \%$ to chloramphenicol. They also noted that $0 \%$ of isolates were resistant to imipenem, whereas in our study $48 \%$ of isolates were resistant to imipenem. Hadi et al. ${ }^{(18)}$ observed that the resistance rates to trimethoprim/ sulfamethoxazole and chloramphenicol were $12.24 \%$ and $32.65 \%$, respectively, which was considerably low in comparison with our study. However, Gündogdu et al. ${ }^{(19)}$ observed that $84 \%$ and $94 \%$ of isolates were resistant to imipenem and tetracycline, which was markedly high in comparison with our current study.
In the present study it was observed that $70 \%$ of isolates had class 1 integrons and $40 \%$ of isolates had class 2 integrons. Fourteen isolates (28\%) jointly had class 1 and class 2 integrons, and 41 (84\%) isolates were integronpositive. The prevalences of isolates with class 1 integrons that were resistant to chloramphenicol, tetracycline, co-trimoxazole, imipenem, streptomycin and nitrofurantoin among $35 \mathrm{E}$. coli isolates were $22.9 \%, 51.4 \%$, $48.6 \%, 57.1 \%, 65.7 \%$, and $17.1 \%$, respectively. Also the prevalences of antibiotic-resistant isolates with class 2 integrons to chloramphenicol, tetracycline, co-trimoxazole, imipenem, streptomycin and nitrofurantoin among $20 \mathrm{E}$. coli isolates were $35 \%, 45 \%, 55 \%$, $40 \%, 70 \%$, and $10 \%$, respectively. Mokracka et al. ${ }^{(29)}$ reported that $E$. coli isolated from one wastewater treatment plant in Poland were resistant to trimethoprim/sulfamethoxazole, amikacin, imipenem, chloramphenicol and tetracycline with percentages of $70.6 \%, 41.3 \%$, $3.7 \%, 52.3 \%$, and $73.4 \%$, respectively. As compared to our results, the authors reported a relatively high occurrence of antimicrobial resistance to all antibiotics except imipenem that exhibited the lowest resistance percentage. The authors also noted that $10.8 \%$ of isolates had class 1 integrons and only $2 \%$ of isolates had class 2 integrons, whereas $2 \%$ of isolates harbored both class 1 and 2 integrons. Their integron results were also very low as compared with our current results. Likewise, Kotlarska et al. ${ }^{(30)}$ reported that $20 \%$ of E. coli strains isolated from wastewater were resistant to trimethoprim/sulfamethoxazole. Among those, $32.6 \%$ of isolates had class 1 integrons and just $3.5 \%$ of isolates had class 2 integrons, whereas $0.38 \%$ of isolates had jointly class 1 and 2 integrons. Diwan et al. ${ }^{(31)}$ reported the antibiotic resistance in E. coli isolates from hospital wastewater in India, showing the highest resistance to amikacin. It was also observed that antimicrobial resistance rates were significantly higher in hospital sewage isolates than in hospital clinical isolates in Taiwan. ${ }^{(32)}$ 
Integrons contain mobile gene cassettes that encode resistance to antibiotics. We did not investigate the gene cassettes within the integrons studied, which is a limitation of the current study. The use of molecular typing of the isolates may be able to elucidate genetic relationships between the strains under study.

\section{CONCLUSION}

This study demonstrated a high number of class 1 and class 2 integrons among E.coli strains isolated from hospital wastewaters in Tehran city. Therefore, the use of appropriate strategies for the elimination and decrease of antibiotic resistance is necessary.

\section{ACKNOWLEDGMENTS}

We would like to thank the Clinical Research Development Center of Baqiyatallah hospital for their kind cooperation. This study was supported in part by a grant from the Clinical Research Development Center of Baqiyatallah hospital.

\section{CONFLICT OF INTEREST}

The authors declare that they have no conflicts of interests

\section{CONTRIBUTORS}

RR designed the study and analyzed the data. MZ performed laboratory work. NS contributed to data analysis and AAK revised the manuscript. All authors have read and approved the final manuscript.

\section{REFERENCES}

1. Li L, Dechesne A, He Z, et al. Estimating the transfer range of plasmids encoding antimicrobial resistance in a wastewater treatment plant microbial community. Environ Sci Tech Let 2018;5:260-5. doi: 10.1021/acs.estlett.8b00105.

2. Farshad S, Anvarinejad M, Tavana AM, et al. Molecular epidemiology of Escherichia coli strains isolated from children with community acquired urinary tract infections. Afr J Microbiol Res 2011;5:4476-83. doi: 10.5897/AJMR11.285.

3. Abraham WR. Megacities as source for pathogenic bacteria in rivers and their fate downstream. Int J Microbiol 2011; Article ID 798292, 13 pages. doi: 10.1155/2011/798292.

4. Anvarinejad M, Farshad SH, Ranjbar R, et al. Genotypic analysis of $E$. coli strains isolated from patients with cystitis and pyelonephritis. Iran Red Crescent Med J 2012;14:408-16.

5. Ranjbar R, Hosseini S, Zahraei-Salehi T, et al. Investigation on prevalence of Escherichia coli strains carrying virulence genes ipaH, estA, eaeA and $\mathrm{bfpA}$ isolated from different water sources. Asian Pac J Trop Dis 2016;6:278-83. DOI: https:/ /doi.org/10.1016/S2222-1808(15)61031-3.

6. Geue L, Monecke S, Engelmann I, et al. Rapid microarray- based DNA genoserotyping of Escherichia coli. Microbiol Immunol 2014;58:7786. doi: 10.1111/1348-0421.12120.

7. Croxen MA, Finlay BB. Molecular mechanisms of Escherichia coli pathogenicity. Nat Rev Microbiol 2010;8:26-38. doi: 10.1038/nrmicro2265.

8. Jahandeh N, Ranjbar R, Behzadi P, et al. Uropathogenic Escherichia coli virulence genes: invaluable approaches for designing DNA microarray probes. Cent European J Urol 2015;68:452-8. doi: 10.5173/ceju.2015.625.

9. Dubois V, Debreyer C, Quentin C, et al. In vitro recombination catalyzd by bacterial class 1 integron integras Intl1 involves cooperative binding and specific oligomeric intermediates. PLoS ONE 2009;4: e5228. doi: 10.1371/ journal.pone.0005228.

10. Stalder T, Barraud O, Casellas M, et al. Integron involvement in environmental spread of antibiotic resistance. Front Microbiol 2012;3:119. doi: 10.3389. fmicb. 00119.

11. Naghoni A, Ranjbar R, Tabaraie B, et al. High prevalence of integron-mediated resistance in clinical isolates of Salmonella enteria. Jpn J Infect Dis 2010;63:417-21.

12. Chen B, Weiwen Z, Ying Y, et al. Class 1 integrons, selected virulence genes, and antibiotic resistance in Escherichia coli isolates from the Minjiang river, Fujian province, China. Appl Environ Microbiol 2011;77: 148-55. doi:10.1128/ AEM.01676-10.

13. Behzadi P, Najafi A, Behzadi E, et al. Microarray long oligo probe designing for Escherichia coli: an in-silico DNA marker extraction. Cent European J Urol 2016;69:105. doi: 10.5173/ ceju.2016.654.

14. Partridge SR, Tsafnat G, Coiera E, et al. Gene cassette and cassette arrays in mobile resistance 
integrons. FEMS Microbiol Rev 2009;33:757-84. doi: 10.1111/j.1574-6976.2009.00175.x.

15. Moura A, Soares M, Pereira C, et al. Integral: a database and search engine for integrons, integrases and gene cassettes. Bioinformatics 2009;25:1096-8. doi: 10.1093/bioinformatics/ btp105.

16. Reinthaler FF, Posch G, Feierl G, et al. Antibiotic resistance of E.coli in sewage and sludge. Water Res 2003;37:1685-90.

17. Elmanama AA, Elkichaoui AY, Mohsin M. Contribution of hospital wastewater to the spread of antibiotic resistance in comparison to nonhealth institution. J Al-Aqsa Univ 2006;10:10821.

18. Hadi M, Shokoohi R, Ebrahimzadeh A, et al. Antibiotic resistance of isolated bacteria from urban and hospital wastewater in Hamedan city. Iran J Health Environ 2011; 4:106-13.

19. Gündogdu A, Jennison AV, Smith HV, et al. Expended- spectrum $\beta$-lactamase producing Escherichia coli hospital wastewaters and sewage treatment plants Queensland, Australia. Can J Microbial 2013;59:737-45. doi: 10.1139/cjm-20130515.

20. Khan A, Rind R, Shoaib M, et al. Isolation, identification and antibiogram of Escherichia coli from table eggs. J Anim Health Prod 2016;4:1-5. doi: 10.14737/journal.jahp/2016/4.1.1.5.

21. Clinical and Laboratory Standards Institute. Performance standards for antimicrobial susceptibility testing: twenty- second information supplement. Wayne PA: Clinical and Laboratory Standards Institute;2012.

22. Roe MT, Vega E, Pillai SD. Antimicrobial resistance markers of class 1 and class 2 integronbearing Escherichia coli from irrigation water and sediments. Emerg Infect Dis 2003;9:822-6. doi: 10.3201/eid0907.020529.

23. Sunde M. Prevalence and characterization of class 1 and class 2 integrons in Escherichia coli isolated from meat and meat products of Norwegian origin. J Antimicrob Chemother 2005; 56:1019-24.

24. Exner M, Bhattacharya S, Christiansen B, et al. Antibiotic resistance: what is so special about multidrug-resistant Gram-negative bacteria? GMS Hyg Infect Control 2017;12. doi: 10.3205/ dgkh000290.
25. Larsson DJ. Antibiotics in the environment. Upsala J Med Sci 2014; 1;119:108-12. doi: 10.3109/ 03009734.2014.896438.

26. Kuchenmüller T, Abela-Ridder B, Corrigan T, et al. World Health Organization. initiative to estimate the global burden of foodborne diseases. Rev Sci Tech 2013;32:459-67.

27. Ranjbar R, Masoudimanesh M, Dehkordi FS, et al. Shiga (Vero)-toxin producing Escherichia coli isolated from the hospital foods; virulence factors, o-serogroups and antimicrobial resistance properties. Antimicrob Resist Infect Control 2017;6:4. doi: 10.1186/s13756-016-0163-y.

28. Tajbakhsh E, Khamesipour F, Ranjbar R, et al. Prevalence of class 1 and 2 integrons in multidrug resistant Escherichia coli isolated from aquaculture water in Chaharmahal Va Bakhtiari province, Iran. Ann Clin Microbiol Antimicrob 2015;14:37. doi: 10.1186/s12941-015-0096-y.

29. Mokracka J, Koczura R, Jablonska L, et al. Phylogenetic groups, virulence genes and quinolone resistance of integron-bearing Escherichia coli strains isolated from a wastewater treatment plant. Antonie Van Leeuwenhoek 2011;99:817- 24. doi: 10.1007/ s10482-011-9555-4.

30. Kotlarska E, Luczkiewicz A, Pisowacka M, et al. Antibiotic resistance and prevalence of class 1 and 2 integrons in Escherichia coli isolated from two wastewater treatment plants, and their receiving water (Gulf of Gdansk, Baltic sea, Poland). Environ Sci Pollut Res 2015;22:2018-30. doi 10.1007/s11356-014-3474-7.

31. Diwan V, Tamhankar AJ, Khandal RK, et al. Antibiotic and antibiotic resistant bacteria in water associated with a hospital in Ujjain, India. BMC Public Health2010;10:414. doi: 10.1186/1471-2458$10-414$.

32. Yang CM, Lin MF, Liao PC. Comparison of antibiotic resistance patterns between clinical and sewage isolates in a regional hospital in Taiwan. Lett Appl Microb 2009;48:560-5. https://doi.org/ 10.1111/j.1472-765X.2009.02572.x. 